\title{
AKILLI ŞEBEKELERDE HABERLEŞME TEKNOLOJİSİ KULLANIMI
}

\author{
Pınar UZUN*1- İsmail TEMIZ² \\ ${ }^{1}$ Kırklareli Üniversitesi, Teknoloji Fakültesi, Mekatronik Mühendisliği, Kırklareli \\ ${ }^{2}$ Marmara Üniversitesi, Teknoloji Fakültesi, Mekatronik Mühendisliği, İstanbul
}

$\ddot{O} z$

Günümüz elektrik şebekelerinin dayandığı altyapı ve kaynakların doğaya zarar vermesi, yetersiz ve emniyetsiz olması sorun teşkil etmektedir. Bu nedenle uzun zamandır verimli, emniyetli ve doğa dostu şebekeye dönüşüm çalışmaları yürütülmektedir. Bu çalışmalar akıllı şebeke kavramını ortaya çıarmaktadır. Hem üreticiyi hem de tüketiciyi düşünen bu kavram için önemli bir alt başlık ise haberleşmedir. Gelişen teknoloji ile birçok farklı haberleşme teknolojisi ortaya çıkmıştır. $\mathrm{Bu}$ haberleşme sistemlerinin kendilerine özgü standart ve kullanım alanları vardır. Bu standart ve kullanım alanları göz önüne alınarak akıllı şebeke uygulaması için verimli ve uygun haberleşme sistemini seçmek gerekmektedir.

Anahtar Kelimeler: Akıllı şebeke, Haberleşme, Veri aktarımı, Standartlar

\section{USAGE OF COMMUNICATION TECHNOLOGY ON SMART GRID}

\begin{abstract}
The fact that the infrastructure and resources on which today's electricity grids are based are insufficient, insecure and harmful to nature poses a problem. For this reason, efforts to transform into an efficient, safe and environmentally friendly network have been carried out for a long time. These studies reveal the concept of smart grid. An important subheading for this concept, which considers both the producer and the consumer is communication. With the developing technology, many different communication technologies have emerged. These communication systems have their own standards and usage areas. Considering this standard and its usage areas, it is necessary to choose a suitable and efficient communication system for smart grid application.
\end{abstract}

Keywords: Smart grid, Communication, Data transfer, Standarts

Sorumlu Yazar: Pınar UZUN, pinaruzun@klu.edu.tr 


\section{GİRIŞ̧}

Günümüz teknolojilerinin büyük bir hızla ilerlemesine bağlı olarak elektrik ihtiyacı da artmaktadır. Elektrik ihtiyacının karşılanması için kurulan güç sistemlerinin temeli 1883 yılında Tesla tarafından yayınlanan tasarım esaslarına dayanmaktadır [1]. Ortaya çıktığg zamanın teknolojileri için bu temel yeterli olsa da günümüz gelişen teknolojilerine bağlı ihtiyaçlar göz önüne alındığında yetersiz kalmaktadır. Bu ihtiyaçlar neticesinde enerji üretimi, dağıtımı ve kullanımını kapsayan elektrik şebekelerinin daha verimli, güvenli, kaliteli, doğa dostu ve yönetilebilir olması için "Akıllı Şebeke (Smart Grid)" kavramı ortaya çıkmıştır. Bu çalışmada akıllı şebekeler için haberleşme teknolojileri, protokoller ve haberleşme sistemleri için güvenlik konuları incelenmiştir.

Akıllı şebeke sistem elemanlarına örnek olarak; güneş panelleri, rüzgâr türbinleri, eviriciler, akıllı sayaçlar, iletim hatları, akıllı sensörler, akıllı ev aletleri, hibrit araçlar vb. gösterilebilir. Son zamanlarda akıllı şebeke sistem ve elemanları önem kazanmış; yarı iletken teknolojilerinin yanı sıra kontrol sistemleri, haberleşme ve bilgi teknolojileri (BT) gibi birçok farklı alanda akıllı şebeke sistemlerini geliştirmeye yönelik çalışmalar yürütülmeye başlanmıştır [2-14].

Akılı şebekelerin görevleri şu şekilde sıralanabilir [15]:

* Son kullanıcı olan tüketicilerin aktif olarak sisteme dâhil edilmesini sağlamak.

* Enerjinin üretim aşamasından depolama aşamasına kadar tüm kaynakların sistemle bütünleşmesini sağlamak.

* Geniş alana sahip iletişim ağları, sunucular, ağ geçitleri vb. haberleşme araçları ile bütün sistemi anlık olarak takip edebilmek.

* Dağıtım işlemini sürekli izleyip enerji akışını tahmin etmek amacıyla gerilim, akım ve güç faktörünü eş zamanlı olarak okuyarak, enerji kalitesi için Volt-VAR kontrolü sağlamak.

* Elektrik enerji piyasasını oluşturan; üretim, iletim, dağıtım, piyasa işletimi, toptan satış, perakende satış, ithalat ve ihracat faaliyetleri ile bu faaliyetlere ait iş ve işlemlerini ve bunlarla birlikte serbest tüketici olarak bilinen son kullanıcılar için enerji çeşitliliği ve tercihini sağlamak.

* İletim ve dağıtım sistem elemanlarının birbirleriyle tam olarak bütünleşmesini sağlayarak, enerji piyasası içinde hâli hazırda bulunan kaynaklar ile yeni kaynakların işlevselliğini arttırarak enerji kalitesini sağlamak. 
Akıllı şebeke uygulamaları temel olarak üç alt başlıkta toplanabilir:

i. Dağıtık Üretim Uygulamaları: Akıllı şebekelerin gelişmeler ile birlikte küçük ölçekli enerji üretiminden daha büyük ve yüksek güçleri kapsayan enerji üretimine kadar birçok farklı enerji kaynaklarının entegrasyonuna imkan sağlaması beklenmektedir [16]. Tek ve genel bir üretim ya da depolama merkezinden ziyade özellikle yenilenebilir enerji kaynakları ile haneler kendi enerji ihtiyaçlarını karşılayabilecektir. Böylece üretim, tüketim ve dağıtımdaki kayıplar azalırken enerji verimliliği sağlanmış olacaktır.

ii. Dağıtık Depolama Uygulamaları: Akıllı şebeke sistemlerinde ihtiyaçtan fazla üretilen enerjinin şebekeye dağılmış sistemlerde depolanıp ve ihtiyaç durumunda enerji talebini karşılamak için kullanılması hedeflenir [17]. Bu hedefin gerçekleştirilmesi ile akıllı şebekelerde enerji sürekliliği sağlanmış olacaktır.

iii. Talep Odaklı Yük Yönetimi Uygulamaları: Dağıtık üretim ve depolama uygulamalarına sahip akıllı şebekelerde üretim-talep dengesi, son kullanıcı olan tüketicinin bilinçlendirilmesi ve dinamik fiyat uygulamaları ile daha akıllı yönetilebilir. Talebin fazla olduğu zaman aralıklarında mevcut akıllı şebeke elemanlarının kısa devre akım limitleri ile ısıl dayanım kapasiteleri zorlanmaktadır. Talebe bağlı olarak yürütülecek, talep kaydırma gibi yük yönetimi uygulamaları enerji verimliliğini önemli ölçüde arttıracaktır [17].

Akıllı şebekeler için bahsedilen bu üç temel uygulama için en önemli unsur kontrol ve haberleşmedir. Gelecekte kullanılması planlanan elektrik şebekeleri bilgisayarlar ve veri iletim ağları gibi teknolojilerden faydalanarak ölçme, uzaktan okuma ve izleme, gerekli durumlarda kontrol ve koruma yapabilmelidir. Bu uygulama ve amaçlarla akıllı bir şebekeye ait yapısal katmanlar Şekil 1'de modellenmiştir.

* Güç katmanı: Güç üretimi, iletimi, dağıtımı, depolanması ve tüketilmesi ile ilgili katman.

* Kontrol katmanı: Veri toplamayı ve aktarmayı sağlayan akıllı sensör, ölçme ve sürücü sistemlerini bulundurur.

* Veri İletişim Katmanı: Hatasız ve etkili bir veri iletişimi sağlar.

* Güvenlik Katmanı: Verinin gizliliği, güvenliği, doğruluğu ve şifrelenmesi gibi fonksiyonları yerine getirir. 
Uygulama Katmanı: Birçok farklı amaçlı güç ve enerji uygulamalarında bilgi teknolojilerine dayanan kararların alınması için destek sağlar.

Geleceğin akıllı enerji şebekelerinin bu katmanların iç içe geçmesi ile oluşması beklenmektedir. Böylece hane ve belirli bir mahallî alan düzeyinde ve ülke ölçeğinde faydalı yansımalar elde edilmesi amaçlanmaktadır.

\section{Uygulama Katmanı}

\section{Güvenlik Katmanı}
WAN
AMI
NAN ve FAN
HAN, BAN, IAN
Haberleşme
Katmanı

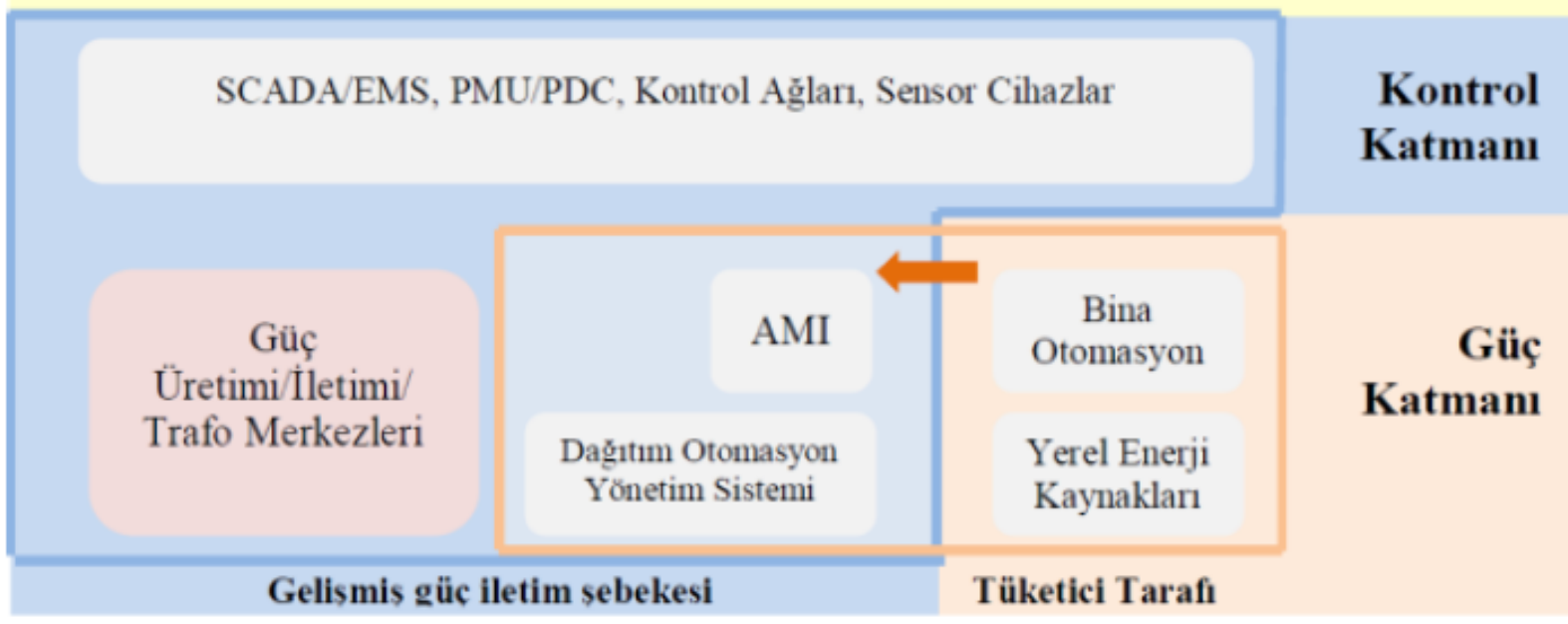

Şekil 1. Akıllı şebeke katmanları modeli [18]

\section{AKILLI ŞEBEKELERDE HABERLEŞME}

Akıllı şebeke; temel olarak bilgi, haberleşme ve operasyon sistemlerinin birleşimi ile şekillenmiş elektrik dağıtım şebekesi şeklinde özetlenebilir. Bu sistemlerin birleşimi sonucu akıllı elektrik şebekeleri; veriler için algılama, toplama, iletme, değerlendirme ve depolama işlemlerini 
gerçekleştirmelidir. Üretim ve tüketimde alternatifler sunan, tüketiciyi aktif hale getiren akıllı şebeke sistemleri geleneksel elektrik şebekelerine kıyasla daha karmaşıktır. Aktif olarak haberleşme ve kontrolün sağlanması ihtiyacını karşılamak için şebeke bileşenleri; veri alma, veri işleme ve veri iletebilmelidir. Bu işlemlerin gerçekleşebilmesi için de bileşenlerin haberleşme yeteneği dışında programlanabilmeleri de gerekmektedir. Bu programlanabilen ve haberleşmesi gereken bileşenlerin birbirleri arasında kurulacak iletişim ve etkileşim için haberleşme protokolleri (TCP/IP benzeri), haberleşme altyapılarına (modemler, yönlendiriciler, kablosuz haberleşme sistemleri) ve sunuculara ihtiyaç duyulur [19].

Akıllı şebekeler, enerjinin üretiminden tüketimine kadar her aşamada gerçek zamanlı ve iki yönlü veri aktarımı sağlayarak, sürdürülebilir, güvenilir ve enerji verimliliği yüksek bir enerji ağı sunmaktadır. Burada bahsedilen tüm koşullar; gelişen yariletken teknolojisi başta olmak üzere, hassas mikroişlemciler ve birçok elektronik ve mekanik eleman sayesinde üretim-iletim-tüketim hatları boyunca sağlanır. Bu durumlar, ileri kontrol dolayısıyla ileri haberleşme yöntemlerine ihtiyaç doğurur. Bu nedenle akıllı şebekeler için kullanılacak haberleşme ağları bu ihtiyaçları karşılayacak, veri yükü ve trafiğini kaldıracak şekilde tasarlanmalıdır.

Akıllı şebekelerde kullanılması planlanan akıllı sayaçlar örnek bir haberleşme uygulaması olarak verilebilir. Sayaç endekslerinin uzaktan okunması için literatürde farklı haberleşme yöntemleri kullanılmıştır [20]. Bu haberleşme yöntemleri tek yönlü olabileceği gibi çift yönlü de olabilmektedir. Endeks bilgileri tek yönlü olarak takip edilebilirken, çift yönlü olarak kullanıcıya da bu bilgiler iletilebilir ya da uzaktan kontrol sağlanarak enerji kesme gibi müdahaleler yapılabilir. Kullanılan sistemlerde yıllık abone tüketimi ve transformatör tüketimlerine bakılarak usulsüz enerji kullanımı da tespit edilmektedir [20].

Akıllı şebeke sistemlerinin mimarisinde haberleşme ihtiyacı; bina ve/veya tesis içi olan yakın alan ve şehir içi ya da şehirlerarası olan uzak alan haberleşmelerinin her ikisini de kapsamalıdır. Gerçek zamanlı haberleşme, elektrik şebekelerinin optimizasyonu ve modernleşmesi açısından önemli bir adım olacaktır. Böylece veri merkezleri, üretici ve tüketici tabanlı yazılım ve uygulamalar ile bu sistem üzerinden veri aktarımını gerçekleştirebilecektir. Verilerin ölçüm noktalarından değerlendirme noktasına aktarılabilmesi için daha basit ve etkili haberleşme teknolojilerinin kullanımı planlanmaktadır. Planlanan haberleşme altyapısı günümüzde fiber optik kablolar, güç 
hattı aracılığı ile geniş bant ve kablosuz teknolojiler içeren çeşitli iletişim yolları kullanılarak inşa edilmektedir. 2012 yılında yapılan bir çalışma ile akıllı şebeke teknolojisinde kullanılan ve kullanılması beklenen haberleşme teknolojilerini özetlemek amacıyla Tablo 1 hazırlanmıştır [18]. Ancak zaman içerisinde Tablo 1'de bulunan teknolojiler haricinde gelişen diğer haberleşme teknolojilerinin de akıllı şebeke sisteminde gerekli parametrelerin analizi ile seçilerek kullanılabileceği öngörülmektedir.

\subsection{Kablolu Haberleşme Teknolojileri}

Elektrik şebekelerinde özellikle uzun mesafelerde veri aktarımı için fiber optik ve iletim/dağıtım hatları en uygun teknolojilerdir. Senkron Optik A $\breve{g}$ - SONET ve Senkron Dijital Hiyerarşi - SDH gibi gelecek kuşak fiber optik teknolojiler de veri aktarımı için kullanılabilir. Bahsedilen teknolojiler IP ve Ethernet uygulamaları için çok servisli platformlar sağlayabilirler. Özellikle Ethernet'in basit olması ve SONET / SDH teknolojisi ile düşük maliyetle "Taşıyıcı Ethernet" oluşturulabilir. Böylece akıllı şebekeler için güvenli ve kaliteli bir veri aktarım ortamı oluşturulur. Elektrik şebekelerinde iletim/dağıtım hatları, uzaktan veri okuma, yük kontrolü sağlama vb. uygulamalar için Güç Hattı Haberleşmesi - PLC de yaygın biçimde kullanılmaktadır. Sinyalizasyon; yüksek gerilim - YG hatlarında kullanılırken, veri aktarımı; orta gerilim - OG ve alçak gerilim - AG hatları üzerinden gerçekleştirilir. PLC, kHz frekanslarında dar bant haberleşme, $\mathrm{MHz}$ frekanslarında ise geniş bant haberleşme sağlar. Var olan elektrik hatları kullanılarak, bu hatlara zaten bağlanmış bulunan cihazlarla haberleşme sağlaması PLC için avantajdır. Buna rağmen; haberleşme empedansı ve kanal koşullarındaki değişimler, büyük alanlarda uygulama problemleri, şebekedeki anahtar sayısının fazla olması, işaret zayıflaması, sinyal girişimi yaratması ve buna maruz kalması, bakım maliyetleri gibi zorlukları da bulunmaktadır [21].

\subsection{Kablosuz Haberleşme Teknolojileri}

Akı1lı şebeke sistemleri için haberleşme prosedürlerine bakıldığında; kablosuz bağlantı, yüksek esneklik (kontrol noktası değiştirme kolaylığı), kolay genişletilebilme, kolay bakım ve düşük uygulama maliyeti (özellikle fiber optik ile karşılaştırıldığında) sayesinde güç sistemi uygulamalarında kontrol ve izleme bilgilerinin iletilmesi için büyük avantajlar sağlar [22]. 
Akıllı şebeke sistemlerinde kullanılabilecek kablosuz haberleşme teknolojileri 3 ayrı gruba ayrılarak incelenebilir. Bu kablosuz teknolojilerden birçoğu tescillenmiş ve oturmuş standartlar tarafından yönetilmekteyken, bazıları açık ve gelişmekte olan standartlar tarafından yönetilmektedir, bazıları ise erken adaptasyon aşamasındadır [23].

i. GSM/Mobil Illetişim ağları: Hücresel haberleşme teknolojileri olarak da bilinirler. Ses aktarımı için tasarlanmış teknolojilerdir. GPRS, $2 \mathrm{G}, 3 \mathrm{G}, 4 \mathrm{G}, 4.5 \mathrm{G}$ ve $5 \mathrm{G}$ vb. iletişim protokolleri içermektedir [24]. 2G teknolojisi, GSM (Global System for Mobile Cummunication) şebeke erişimi için TDMA (Time Division Multiple Access) erişim tekniğini kullanır. Güncellenerek, genel Paket Radyo Servisi - GPRS olmuş ve paketlenmiş veri aktarımı için kullanılır hale gelmiştir. Zamanla, EDGE, 3GPP, 3G, 4G ve 4.5G GSM teknolojileri geliştirilmiştir. 3G; yüksek hızda veri aktarımı, daha iyi ses kalitesi ve paket uygulamalar için internet erişimi sağlar. 4G teknolojisi ise hız ve veri aktarım kapasitesini arttırmak için $3 \mathrm{G}$ üzerine geliştirilmiştir. Bu nedenle $4 \mathrm{G}$ teknolojisi hem daha uygun fiyatla kullanıma sunulabilir hem de akıllı şebekeler için uzaktan okuma, izleme ve kontrol uygulamaları için daha kullanılabilirdir. EGPRS (Enhanced GPRS), veri aktarım hızını arttırmak ve ağ kapasitesini iyileştirmek için ortaya çıkmış ve kullanılmaya başlanmıştır.

ii. Wi-Fi ve WiMAX teknolojileri: IEEE $802.11 \mathrm{a} / \mathrm{b} / \mathrm{c} / \mathrm{g} / \mathrm{n}$ ve IEEE 802.16 standartları üzerine geliştirilmişlerdir. Wi-Fi (Wireless Fidelity), IEEE 802.11n standardı üzerine kurulmuştur, LAN (Local Area Network) düzeyinde erişim sağlar. Mobil cihazların, yakınlarında bulunan kablosuz erişim noktaları aracılığıyla yerel alan ağına bağlanıp ses ve veri aktarımını sağlar. WiMAX, IEEE 802.16 standardı üzerine kurulmuştur. Kablolara alternatif olarak geniş bant iletişimi ile birlikte sayaç okumada daha kaliteli, güvenilir haberleşme ortamı sağlamaktadır.

iii. Kablosuz Gözlü (Mesh) Ağlar (WMN) ve Kablosuz Sensör Ağlar (WSN): IEEE 802.11 ve IEEE802.1.5.4 standartları üzerine kurulmuşlardır. WMN, düşük güç ve veri aktarım oranına sahiptir. WSN ise ev, ofis ve enerji otomasyonu için kullanılır. 
Tablo 1. Akıllı elektrik şebekelerinde kullanılan ve kullanılması beklenen haberleşme teknolojileri [21]

\begin{tabular}{|c|c|c|c|c|}
\hline $\begin{array}{l}\text { Haberleşme } \\
\text { Teknolojisi }\end{array}$ & Türü & Kullanım Şekli & Avantajları & Dezavantajları \\
\hline \multirow{3}{*}{$\begin{array}{l}\text { Kablosuz } \\
\text { Haberleşme } \\
\text { Teknolojileri }\end{array}$} & $\begin{array}{c}\text { Hücresel } \\
\text { (GPRS/3G/4G) } \\
\text { ve LTE }\end{array}$ & $\begin{array}{l}\text { Ses iletişimi, } \\
\text { Yerel enerji kaynakları } \\
\text { ve trafo merkezleri için } \\
\text { uzaktan izleme, } \\
\text { Basit metin } \\
\text { mesajlaşmasını destekler }\end{array}$ & $\begin{array}{l}\text { Mevcut şebeke } \\
\text { altyapısının kullanılması } \\
\text { ile düşük uygulama, } \\
\text { işletme ve bakım maliyeti, } \\
\text { Geniş kapsama alanı } \\
\text { dolayısıyla daha iyi } \\
\text { hareket yeteneği }\end{array}$ & $\begin{array}{l}\text { Kule / Baz istasyonu } \\
\text { ihtiyacı, } \\
\text { Büyük ölçekli } \\
\text { uygulamalarda } \\
\text { ekonomik olmayışı, } \\
\text { Merkezden uzak } \\
\text { bölgelerde kapsama } \\
\text { alanı sorunu, } \\
\text { Güvenlik zafiyeti }\end{array}$ \\
\hline & $\begin{array}{c}\text { Wi-Fi } \\
(\text { IEEE 802.11) }\end{array}$ & $\begin{array}{l}\text { Ses ve görüntü iletişimi, } \\
\text { Ev enerji ara yüzü, } \\
\text { Bilgisayarlar, elektronik } \\
\text { cihazlar ve akıllı ölçme } \\
\text { sistemleri arasında } \\
\text { bağlantı oluşturur }\end{array}$ & $\begin{array}{l}\text { Hızlı tesis etme, } \\
\text { Yüksek esneklik, } \\
\text { Şehir tipi yoğun } \\
\text { bölgelerde uygulanabilme }\end{array}$ & $\begin{array}{l}\text { Yüksek girişime karşı } \\
\text { hassas, } \\
\text { Kapsama alanı dar, güç } \\
\text { tüketimi yüksek, } \\
\text { Küçük ölçekli } \\
\text { uygulamalarda } \\
\text { ekonomik değil, } \\
\text { Güvenlik zafiyeti }\end{array}$ \\
\hline & $\begin{array}{c}\text { WiMAX } \\
\text { (IEEE 802.16) }\end{array}$ & $\begin{array}{l}\text { 3. seviye (müşteri) } \\
\text { iletişim ağları için } \\
\text { kablosuz ağlara } \\
\text { alternatif, } \\
\text { Akıllı sayaç okuma } \\
\text { sistemleri altyapısı }\end{array}$ & $\begin{array}{l}\text { Kablolu çözümlere göre } \\
\text { hızlı kurulum, } \\
\text { Uzun menzilli, } \\
\text { Gerçek zaman } \\
\text { uygulamaları ve erken } \\
\text { yanıt hızının yeterliliği }\end{array}$ & $\begin{array}{l}\text { Kule/ Baz istasyonu } \\
\text { gerektirir, } \\
\text { Güç tüketimi yüksek, } \\
\text { Güvenlik zafiyeti }\end{array}$ \\
\hline \multirow[b]{2}{*}{$\begin{array}{c}\text { Kablolu } \\
\text { Haberleşme } \\
\text { Teknolojileri }\end{array}$} & $\begin{array}{c}\text { SONET / SDH } \\
\text { ve E / GPON }\end{array}$ & $\begin{array}{l}\text { Fiber optik iletim } \\
\text { ortamı, Geniş bantlı } \\
\text { çözümler }\end{array}$ & $\begin{array}{l}\text { Yüksek kapasite ve bant } \\
\text { genişliği; hılı iletişim, } \\
\text { girişim olmaması. }\end{array}$ & $\begin{array}{l}\text { Kurulum hızının yavaş } \\
\text { olması ve yüksek } \\
\text { maliyetli (altyapısız } \\
\text { yerlerde) }\end{array}$ \\
\hline & $\begin{array}{l}\text { PLC (NB ve } \\
B B) \text { ve BPL }\end{array}$ & $\begin{array}{l}\text { Güç iletim hatları, } \\
\text { Haberleşme OG ve AG } \\
\text { hatları üzerinden yapılır, } \\
\text { Kablo ve DSL'e } \\
\text { alternatif bir geniş bantlı } \\
\text { erişim ortamı (BPL) }\end{array}$ & $\begin{array}{l}\text { Bina içinde kurulum } \\
\text { kolaylığı, son kullanıcı } \\
\text { cihazlarına yönelik } \\
\text { yüksek esneklik ve } \\
\text { hareket yeteneği, kırsal } \\
\text { bölgeler için iyi bir çözüm }\end{array}$ & $\begin{array}{l}\text { Büyük binalarda } \\
\text { uygulama zorluğu, } \\
\text { Anahtarlama sorunu, } \\
\text { İşaret zayıflamaları ve } \\
\text { kullanılan yükselticilerin } \\
\text { yüksek maliyetli olması, } \\
\text { Girişime maruz kalma } \\
\text { ve girişim yaratma }\end{array}$ \\
\hline \multirow[b]{2}{*}{ Ağ Tipleri } & WMN & $\begin{array}{l}\text { Ağ tipi şebeke, birçok } \\
\text { farklı uygulama } \\
\text { gerçekleştiren süper ağ } \\
\text { yönlendiricileri }\end{array}$ & $\begin{array}{l}\text { Kolay ve uygun maliyetli } \\
\text { kurulum, Yüksek } \\
\text { güvenirlik ve esneklik }\end{array}$ & $\begin{array}{l}\text { Veri yönetiminin zor } \\
\text { olması; lisanssız } \\
\text { bantlarda düşük } \\
\text { denetlenebilme, Standart } \\
\text { yetersizliği, Sabit } \\
\text { giderler }\end{array}$ \\
\hline & $\begin{array}{l}\text { WSN ve WPAN } \\
\text { (IEEE 802.15.4) }\end{array}$ & $\begin{array}{l}\text { Küçük çaplı } \\
\text { uygulamalar, } \\
\text { Ev, ofis ve akıllı enerji } \\
\text { otomasyonu, } \\
\text { Trafo merkezlerinde, } \\
\text { endüstriyel tesislerde ve } \\
\text { yerel üretim birimlerinde } \\
\text { algilama ve izleme }\end{array}$ & $\begin{array}{l}\text { Kolay ve hızlı yayılım, } \\
\text { Düşük maliyet, } \\
\text { Yüksek taşınabilir, Kolay } \\
\text { yapılandırma }\end{array}$ & $\begin{array}{l}\text { Güç ve bellek } \\
\text { kısıtlamaları, } \\
\text { Veri hızının düşük } \\
\text { olması, } \\
\text { Veri kaybının yüksek } \\
\text { olması, } \\
\text { Çok küçük kapsama } \\
\text { alanı }\end{array}$ \\
\hline
\end{tabular}




\subsection{Haberleşme Protokolleri}

\subsubsection{MODBUS Protokolü}

MODBUS, 1979 yılında Modicon firması tarafından kendi ürettikleri PLC'lerde kullanılmak için geliştirilmiş seri kanal haberleşme protokolüdür [16]. Haberleşme yapısı "master-slave" şeklindedir. "Master" yönetiminde "slave” tarafından sağlanan verilerin haberleşmesi sağlanır. Veri okuma isteği "master" tarafından gönderilir. Her bir "slave" için birim numarası (unit ID) atanır ve bu numara sayesinde "master" hangi "slave" ile haberleşme sağlandığını bilebilir. Bir "master" 247 "slave" ile bağlantı kurarak haberleşebilir. MODBUS protokolü üreticisinden bağımsız olarak genişletilebilen, açık kaynak kodlu bir haberleşme protokolü olduğundan kullanımı ücretsizdir. Bu nedenle de MODBUS protokolü günümüzde endüstriyel uygulamalarda yaygın olarak kullanılmaktadır.

MODBUS protokolü genellikle sahalarda kullanılan ölçüm cihazlarından gelen verilerin kontrolcüye iletilmesi için kullanılır. Kullanılan cihaz türü ve iletilen veri türüne bağlı olarak; MODBUS RTU, MODBUS ASCII, MODBUS TCP/IP, MODBUS over UDP ve MODBUS Plus olmak üzere beş farklı protokol geliştirilmiştir. Bu beş protokolden MODBUS RTU seri kanal haberleşmesinde en çok kullanılan protokoldür, Ethernet altyapısında ise MODBUS TCP/IP kullanılır.

\subsubsection{IEC 61850 Protokolü}

IEC 61850; indirici merkezler olan, elektriksel şebekelerde veri haberleşmesi ve elektriksel trafo merkezlerinin modellenmesi için kullanılan uluslararası endüstriyel haberleşme protokolüdür [25]. Uluslararası Elektroteknik Komisyonu (International Electrotechinacal Commission - IEC) Teknik Komitesi (TC57) tarafından geliştirilmiş, modellenebilir bir haberleşme standardıdır. Akıllı Elektronik Cihazlar (Intellegent Electronic Devices - IED) ve trafo merkezleri arasında veri ve komut aktarımını gerçekleştirir. Bu protokol, endüstriyel haberleşme ağlarında geçmişten günümüze kullanılan diğer haberleşme protokollerinde bulunmayan ya da iyileştirilmesi gereken ihtiyaçlara göre, veri ağı üzerinden kullanılacak şekilde tasarlanmıştır. Bu standart indirici merkezler harici diğer tüm elektrik sistemleri için de haberleşme standardı olarak kullanabileceği ve yeni bilgi modelleriyle geniş kapsamlara ulaşılabileceği gözlemlenmiştir. Böylece bu standart; 
rüzgâr ve hidroelektrik santraller, elektrik iletim ve dağıtımı, sistem değişkenlerinin görüntülenmesi ve dağıtık enerji kaynaklarının uygulanması için birçok çalışmalar yapılmış ve hala yapılmaktadır [26]. Sistematik tasarımı, farklı model ve/veya markaların birbirileri ile haberleşmesini sağlaması, hızlı veri aktarımı, güvenilir yapıda olması ve genişletilebilmesi ile akıllı şebeke sistemleri için IEC 61850 protokolü öne çıkmaktadır.

\subsection{Güvenlik}

Akıllı şebeke sistemleri için haberleşme önemli bir konudur. Haberleşme sistemleri talep ve gelişmelere bağlı olarak genişletilebilir olmalıdır. Veri aktarımının zamanında ve güvenli bir şekilde gerçekleşmesi gerekmektedir. Olası bir güvenlik açığı durumunda haberleşme sistemi ve dolayısıyla kontrol sistemleri engellenip sistemlere gerekli müdahalenin yapılmasını kısıtlama, üretim, tüketim verilerinin değiştirilmesi gibi sorunlar ortaya çıkacaktır. Bu sorunlara karşı, olası durumları göz önüne alacak bir güvenlik sistemi tasarlanmalıdır. Bunun için, "Federal Office for Information Security” kurumu tarafından "Akıllı şebekeler ağ geçidi için güvenlik profili” adlı bildiri yayınlanmıştır [27]. Kablolu ve kablosuz veri aktarımları için her durum göz önüne alınarak; güvenlik yöntemleri kullanılır. Kablolu haberleşmede birçok farklı güvenlik uygulamalarını destekleyen ağ yönlendirme cihazları kullanılır ve böylece sadece yetkilendirilmiş cihazlarla haberleşme yapılır. Kablosuz haberleşmede ise güvenliği sağlayabilmek için üç aşamalı bir güvenlik önlemi olan; ağ ismini gizleme (SSID Hiding), fiziksel adrese göre filtreleme (MAC Filtering) ve Yayım sinyali şifreleme (WPA2-PSK) kullanılır [28].

\section{SONUÇ}

Hayatımızda çok önemli bir yer tutan elektrik enerjisi, güçlü ve etkili olmakla beraber alternatif kaynakları da olan hassas bir enerji iletim formudur. Gelişmiş ülkeler göz önüne alındığında, refah ve ekonomi seviyesinin belirlenmesinde de etkin rol almaktadır. Günümüz teknolojik gelişmeleri ile elektrik şebeke altyapısının yetersizliğini gidermek adına birçok farklı çalışma ve yatırım yapılmaktadır. Son zamanlarda artan tüketici taleplerine bağlı olarak enerji tüketim oranları artmıştır. $\mathrm{Bu}$ artış yeni elektrik şebekeleri tesis edilmesi ve bu tesislerin uygun şekilde kontrol edilmesini, enerji kaynaklarının gelişmiş teknolojiler ile elektrik sistemlerine dağıtılmasını 
gerektirmektedir. Yine akıllı şebeke elemanlarının yapısal ve tasarımsal olarak da gelişmeler beklenmektedir. Bütün bu elemanların oluşturduğu enerji sistemleri ve enerji dağıtımında sorumlu elektrik şebekelerinin verimli bir şekilde yönetimi, haberleşme teknolojilerinin imkânlarını kullanabilen sistem mimarileri ile gerçekleştirilebilecektir. Akıllı şebeke uygulamaları birçok farklı kullanım amacına yönelik olduğu gibi bu uygulamalarda kullanılabilecek haberleşme teknolojilerinin her biri de farklı yeteneklere ve özelliklere sahiptir. Bu nedenle akıllı şebekelerde haberleşme altyapıları belirlenirken uygulamalar için belirli koşullar göz önünde bulundurularak en uygun haberleşme teknolojileri kombinasyonu oluşturulmalıdır. Dolayısıyla "akıllı şebeke" kavramının kullanım senaryolarının teknik ve operasyonel ihtiyaçları tespit edilerek bu parametreler göz önünde bulundurulmalıdır. Böylece veri iletiminde verimlilik, güvenlik ve esneklik sağlanmış, kendi kendini iyileştirebilen şebekeler kullanılır olacaktır.

\section{KAYNAKLAR}

[1] Dinçer, H., Mutlu, F., ve Kuzlu, M., Sayısal Teknolojinin Elektrik Şebeke Ağına Katılması: Akıllı Şebeke, IV. Enerji Verimliliği ve Kalitesi Sempozyumu, Kocaeli, 193 - 197, 2011.

[2] Cunjiang, Y., Huaxun, Z., Lei, Z. Architecture Design for Smart Grid, Energy Procedia, Cilt: 17, s:1524-1528, 2012.

[3] Brown, R.E., Impact of Smart Grid on Distribution System Design, IEEE Power and Energy Society General Meeting - Conversion and Delivery of Electrical Energy in the 21st Century, Pittsburgh, PA, s:1-4, 2008.

[4] Bayod-Rujula, A.A., Future Development of the Electricity Systems with Distributed Generation, Energy Cilt: 34, s:377-8, 2009.

[5] Grijalva, S., Tariq, M.U., Prosumer-Based Smart Grid Architecture Enables A Flat, Sustainable Electricity Industry, Innovative Smart Grid Technologies (ISGT) IEEE PES,” s:1-6, 2011.

[6] Kabalci, E., Kabalci, Y., Develi, I., Modelling and Analysis of A Power Line Communication System with QPSK Modem For Renewable Smart Grids, Electrical Power and Energy Systems, Cilt: 34, s:19-28, 2012.

[7] Depuru, S.S.S.R., Wang, L., Devabhaktuni, V., Smart Meters for Power Grid: Challenges, Issues, Advantages and Status, Renewable and Sustainable Energy Reviews, Cilt: 15, s:2736-2742, 2011.

[8] Zhang, Y., Sun, W., Wang, L., Wang, H., Green, R.C., Alam, M., A Multi-Level Communication Architecture of Smart Grid Based on Congestion Aware Wireless Mesh Network, North American Power Symposium (NAPS), Boston, MA, s:1-6, 2011. 
[9] Wang, W., Xu, Y., Khanna, M., A Survey on The Communication Architectures in Smart Grid, Computer Networks, Cilt:55, s:3604-3629, 2011.

[10] Rengaraju, P., Lung, C.H., Srinivasan, A., "Communication Requirements and Analysis of Distribution Networks Using Wimax Technology For Smart Grids", Eighth International Wireless Communications and Mobile Computing Conference (IWCMC), s:666-670, 2012.

[11] Parikh, P., Kanabar, M., Sidhu, T., Opportunities and Challenges of Wireless Communication Technologies for Smart Grid Applications," IEEE Power and Energy Society General Meeting, s:1-7, 2010.

[12] Galli, S., Scaglione, A., Wang, Z., Power Line Communications and the Smart Grid, First IEEE International Conference on Smart Grid Communications (SmartGridComm), s:303-308, 2010.

[13] Yi, P., Iwayemi, A., Zhou, C., Developing ZigBee Deployment Guideline Under WiFi Interference for Smart Grid Applications, IEEE Transactions on Smart Grid, Cilt: 2, s:110-120, 2011.

[14] Jarventaustaa, P., Repoa, S., Rautiainena, A., Partanenb, J., Smart Grid Power System Control in Distributed Generation Environment, Annual Reviews in Control, Cilt: 34, s: 277-286, 2010.

[15] Yazıcı, F., Başoğlu, M.E. ve Çakır, B., Akıllı Şebeke Bileşenleri ve Yapısal Analiz, EMO Bilimsel Dergi, Cilt 8, Sayı 2, s:121-127, Aralık, 2018.

[16] Modicon, Modicon Modbus Protocol Reference Guider, 1996.

[17] Şahin, C., Kahraman, Ö., Temiz, A., Smiai, M.S., Alramadan, F.Y., Almutairi, S.S. ve Alshahrani, S., A Smart Control System for PV Generation in LV Distribution, The Saudi Arabia Smart Grid (SASG), Suudi Arabistan, 2012.

[18] Lo, C. H., Ansari, N., The Progressive Smart Grid System from Both Power and Communications Aspects, IEEE Communications Surveys \& Tutorials, Vol. 14, No. 3, 2012.

[19] Akçin, M., Alagöz, B.B., Keleş, C., Karabiber, A. ve Kaygusuz, A., Dağıtık Kontrol ile Akıllı Şebekelerde Geniş-Alan Yönetimi ve Geleceğe Dönük Projeksiyonlar, SAÜ. Fen Bil. Der. 17. Cilt, 3. Say1, s. 457-470, 2013.

[20] Bayındır, R., Demirtaş, K., Akıllı Şebekeler: Elektronik Sayaç Uygulamaları, Politeknik Dergisi, Cilt 17, Sayı 2, s:75-82, 2014.

[21] Usta, Ö., Yumak, K., “Akıllı Elektrik Şebekeleri ve Veri İletişimi-Smart Grid and Data Communication", TMMOB EMO Akıllı Şebekeler ve Türkiye Elektrik Şebekesinin Geleceği Sempozyumu, 2013. 
[22] Gomez, L.A.G., Grilo, A.P., Sallesa, M.B.C., Casella, I.R.S., Capovilla, C.E., Sguarezi Filho, A. J., Wind-DFIG Wireless Controlled Using EGPRS Standard Applied to the Ancillary Services in a Smart Grid Environment, Electric Power Systems Research, Volume 189, 2020.

[23] Baloğlu, A., Karademiroğlu, O., Akıllı Şehirlerde Kablosuz Haberleşme Teknolojileri ve Doğru Teknoloji Seçimi, İstanbul Sabahattin Zaim Üniversitesi Fen Bilimleri Enstitüsü Dergisi, Cilt 1, Sayı 1, s:22-29, 2019.

[24] Hanes, D., Salguerio, G., Grossetete, P., Barton, R., Henry J., IoT Fundamentals: Networking Technologies, Protocols and Use Cases for the Internet of Things, 2017.

[25] Temiz, A., Kahraman, Ö., Şahin, C., Nadar, A, Akıllı Şebekeler İçin Haberleşme Çözümü, Elektrik-Elektronik-Bilgisayar Mühendisliği Sempozyumu ve Fuarı, Bursa, 2008.

[26] Gezer, D., Nadar, A., Özay ve Prof. Dr. N., IEC 61850 Standard1 ve Hidroelektrik Santrallerin Otomasyon Sistemlerine Uygulanmas1, emo.org.tr (26.08.2021).

[27] Federal Office for Information Security, Protection Profile for the Gateway of a Smart Metering System, 2011.

[28] Temiz, A., Kahraman, Ö.F., Şahin, C., Nadar, A., Akıllı Şebekeler İçin Haberleşme Çözümü, TMMOB EMO Akıllı Şebekeler ve Türkiye Elektrik Şebekesinin Geleceği Sempozyumu, 2013. 